\title{
On developing cartographic terminology in African languages
}

\author{
Coetzee Serena ${ }^{\mathrm{a}}$, Cooper Antony $\mathrm{K}^{\mathrm{a}, \mathrm{b}}$, Adeleke A ${ }^{\mathrm{a}}$, Chauke MMM ${ }^{\mathrm{c}}$, Girmay LA ${ }^{\mathrm{a}}$, Katumba S ${ }^{\mathrm{a}}$, \\ Nsubuga FW ${ }^{\mathrm{a}}$, Owusu-Banahene $\mathrm{W}^{\mathrm{d}} \&$ Semoli B ${ }^{\mathrm{e}}$ \\ ${ }^{a}$ Dept Geography, Geoinformatics \& Meteorology, University of Pretoria, Pretoria, South Africa, \{serena.coetzee, \\ adedayo.adeleke,samy.katumba,francis.nsubuga\}@up.ac.za; u19125080@tuks.co.za \\ ${ }^{b}$ Smart Places, CSIR, Pretoria, South Africa, acooper@csir.co.za \\ ${ }^{c}$ NSIF, Dept of Agriculture, Land Reform and Rural Development, Pretoria, South Africa, maroale.chauke@dalrrd.gov.za \\ ${ }^{d}$ Dept Computer Engineering, University Of Ghana, Accra, Ghana,wowusu-banahene@ug.edu.gh \\ ${ }^{e}$ National Geo-spatial Information, Dept of Agriculture, Land Reform and Rural Development, Cape Town, South Africa, \\ bulelwa.semoli@dalrr.gov.za
}

\begin{abstract}
Keywords: Afrikaans, Amharic, isiXhosa, isiZulu, Lingala, Luganda, Sepedi, Setswana, Swahili, Twi, Yoruba, XiTonga, cartography
\end{abstract}

\section{Abstract:}

The mission of the International Cartographic Association (ICA) is to promote the disciplines and professions of cartography and geographical information science (GIScience) in an international context. The ICA is full member of the International Science Council (ISC), formed in 2008 by the merger of the International Council of Science (ICSU) and the International Social Science Council (ISSC). In 2019, the ICA also became an Associate Member of the Open Geospatial Consortium (OGC), an international consortium focusing on the interoperability of geospatial data, applications and services [Trainor 2020]. This allows ICA Commission Members to participate in OGC's standards development.

After joining the OGC, four ICA Commissions and the ICA Working Group on the Cartography Body of Knowledge, started discussions on how the ICA could contribute to the OGC. One area they identified is standardizing terms used in cartography [Coetzee et al, 2021]. We felt that we could make a useful contribution to this by starting to develop the terminology for cartography and GIScience in several African languages - even though we do not claim to be linguists or lexicographers. The ICA published a multi-lingual dictionary of cartography in five European languages [ICA 1973]. De Gruyter published one in 1997, edited by Joachim Neumann and expanded to terms in 25 languages (including Algerian and Moroccan Arabic) but with the definitions in only five European languages [Neumann 1997]. An ebook version was then published [Neumann 2011]. None of these dictionaries included any language from Sub-Saharan Africa.

We document here our experiences with developing terminology and drafting definitions, as our experiences might help others interested in increasing the technical vocabulary of languages with which they are familiar. Table 1 provides our proposed names for the ICA in several African languages. All of these languages are spoken in several countries, so we have provided the country code to indicate the dialect used for the terms. We hope that this inspires others to translate the Association's name into other languages - and not just those used in Africa.

\begin{tabular}{|c|c|c|c|}
\hline Language & Country & Name of the Association & Acronym \\
\hline English & $\mathrm{ZA}$ & International Cartographic Association & ICA \\
\hline Afrikaans & $\mathrm{ZA}$ & Internasionale Kartografiese Vereniging & IKV \\
\hline Amharic & ET & 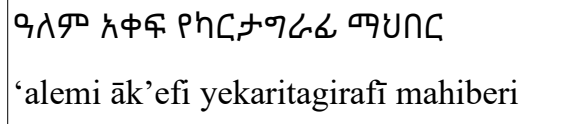 & \\
\hline isiXhosa & $\mathrm{ZA}$ & Umbutho wehlabathi wemephu & \\
\hline
\end{tabular}




\begin{tabular}{ll|l|l}
\hline isiZulu & ZA & Intlangano yomhlaba wonke wamamephu & \\
\hline Lingala & CD & Lingomba Ya Bobongisami Ya Bitando Ya Mokili. & \\
\hline Luganda & UG & Ekibiina kya mawanga ekigata abakubi ba Maapu & \\
\hline Sepedi & ZA & Mokgatlo wa badiradimmepe wa ditšhaba-tšhaba & \\
\hline Setswana & ZA & Mokgatlho wa badiradimmapa wa ditšhabatšhaba & \\
\hline Swahili & UG & Chama cha Katuni cha Kimataifa & \\
\hline Twi & GH & Amansan Akyerekyerckwan-ho-nkitahodie Kuo & \\
\hline Yoruba & NG & Egbe Alaworan Agbaye & EAA \\
\hline XiTsonga & ZA & Nhlangano wa misava hinkwayo wa vampfampfarhuti & \\
\hline
\end{tabular}

Table 1: The ICA's name in several languages

While this might seem like a simple exercise, it highlighted the following issues:

- Does one do a literal translation, and translate each word separately?

- Does one translate two of the words together as a concept, or all three together as a concept?

- Does one borrow some of the terms from English or other languages, such as French, Portuguese or Arabic?

- Does one borrow the whole name of the Association from another language, with or without adaption to the linguistic customs of the target language?

- How does the word order change the meaning and or emphasis of the resulting term?

- Some words in one language have multiple meanings or nuances that are not always captured in another language, and vice versa, such as the English words class, object, point and set.

- Should one also provide a transliteration into the Roman alphabet?

- How should an acronym be created to be useful, particularly as some languages are not set up for English-type acronyms?

The ICA Working Group on the Cartographic Body of Knowledge is reviewing terms related to cartography and will propose revised definitions, and new terms and definitions. They started with the terms: map, cartography, cartographer and cartographic mapping [CartoBOK 2021], and we are examining these. Further, we are exploring the terminology needed for specific cartographic applications, such as a COVID-19 dashboard, to make the information more accessible to those who do not speak well-resourced languages. This includes terms such as classification, map projection and thematic map. This is a complex exercise. For example, in South Africa, it took two decades to develop the terminology needed for the foundation phase dictionaries in all 11 official languages [PANSALB 2019].

Further issues that the process has highlighted include:

- Should a definition be terse or pithy, possibly with notes and examples, according to established rules (as is done by the International Organization for Standardization (ISO) for example), or should a definition be descriptive and if so, how descriptive?

- Several English terms can be translated into one term into the target language, which could give rise to misinterpretation if adequate context is not provided for interpreting the terminology.

- Some languages have extensive resources available online, such as Wikitionary and Wikipedia, while others have few.

- Sometimes, it is easier to translate the English term first into another European language used widely in Africa (such as French) and then translate the term into the target language, rather than doing it straight from English. 